Gerritsen, A.A.M., Bramsen, I., Devillé, W., Willigen, L.H.M. van, Hovens, J.E., Ploeg, H.M. van der Physical and mental health of Afghan, Iranian and Somali asylum seekers and refugees

living in the Netherlands.

Social Psychiatry and Psychiatric Epidemiology: 41, 2006, nr. 1, p. 18-26

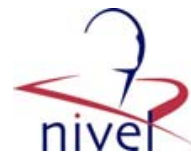

\begin{tabular}{|l|l|}
\hline Postprint Version & 1.0 \\
\hline Journal website & $\underline{\text { http://dx.doi.org }}$ \\
\hline DObmed link & $\begin{array}{l}\text { http://www.ncbi.nlm.nih.gov/entrez/query.fcgi? cmd=Retrieve\&db=pubmed\&dop } \\
\mathrm{t}=\text { Abstract\&list_uids=16341619\&query_hl=5\&itool=pubmed_docsum }\end{array}$ \\
\hline 10.1007/s00127-005-0003-5
\end{tabular}

A. A. M. Gerritsen, PhD $\left(^{*}\right)$. I. Bramsen, PhD . H. M. van der Ploeg, PhD Dept. of Medical Psychology VU University Medical Centre Van der Boechorststraat 7, Room D433 1081 BT Amsterdam, The Netherlands Tel.: +31-20/4448-088 Fax: +31-20/4448-181 E-Mail: aam.gerritsen@vumc.nl

A. A. M. Gerritsen, PhD . I. Bramsen, PhD . H. M. van der Ploeg, PhD Institute for Research in Extramural Medicine VU University Medical Centre Amsterdam, The Netherlands
W. Devillé, MD, PhD

Netherlands Institute for Health Services Research

Utrecht, The Netherlands

L. H. M. van Willigen, MD, PhD Consultancy for Health and Human Rights Amsterdam, The Netherlands

J. E. Hovens, MD, PhD

Delta Bouman Psychiatric Teaching Hospital Poortugaal, The Netherlands

AnNetTe A.M. Gerritsen . Inge BrAmSen . WAlter DeVillé . Loes H.M. VAN WiLligen . JOHANNES E. HOVENS . HENK M. VAN DER PLOEG

\title{
Physical and mental health of Afghan, Iranian and Somali asylum seekers and refugees living in the Netherlands
}

\begin{abstract}
Context Worldwide, the number of refugees and asylum seekers is estimated to be about 11.5 million plus a much larger number of former refugees who have obtained a residence permit in a new country. Although asylum seekers have been coming to the Netherlands since the 1980s, very few epidemiological studies have focused on this group of inhabitants or on the refugees who have resettled in this country. Objectives The objectives of this study were to estimate the prevalence rates of physical and mental health problems and to identify the risk factors for these complaints. Design, Setting, and Participants A population-based study was conducted in the Netherlands from June 2003 to April 2004 among adult refugees and asylum seekers from Afghanistan, Iran and Somalia. Asylum seekers were living in 14 randomly selected reception centres, and random samples of refugees were obtained from the population registers of three municipalities (Arnhem, Leiden and Zaanstad). A total of 178 refugees and 232 asylum seekers participated (response rates of 59 and 89\%, respectively). Main Outcome Measures General health and physical health were measured with the Short Form-36 and a list of 19 chronic conditions, respectively; symptoms of post-traumatic stress disorder (PTSD), depression and anxiety, were measured with the Harvard Trauma Questionnaire and the Hopkins Symptoms Checklist-25. Results More asylum seekers (59.1\%) than refugees $(42.0 \%)$ considered their health to be poor $(\mathbf{P}=0.001)$. In both groups, approximately half of the respondents suffered from more than one chronic condition.
\end{abstract}


Gerritsen, A.A.M., Bramsen, I., Devillé, W., Willigen, L.H.M. van, Hovens, J.E., Ploeg, H.M. van der

Physical and mental health of Afghan, Iranian and Somali asylum seekers and refugees

living in the Netherlands.

Social Psychiatry and Psychiatric Epidemiology: 41, 2006, nr. 1, p. 18-26

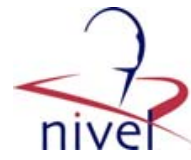

More asylum seekers than refugees had symptoms of PTSD (28.1 and 10.6\% respectively; $\mathbf{P}=0.000$ ) and depression/anxiety (68.1 and 39.4, respectively; $\mathbf{P}=0.000$ ). Respondents from Afghanistan and, in particular, from Iran had a higher risk for PTSD and depression/anxiety. Female gender was associated with chronic conditions, PTSD and depression/ anxiety, and higher age was associated with poor general health and chronic conditions. A greater number of traumatic events were associated with all health outcomes, and more post-migration stress and less social support was associated with PTSD and depression/ anxiety symptoms. Conclusions Both physical and mental health problems are highly prevalent among refugees and asylum seekers in the Netherlands. Although higher prevalence rates for most health outcomes were found among asylum seekers, both the specific health services for asylum seekers and the general health services in the municipalities should be aware of these problems.

\section{INTRODUCTION}

Worldwide, the number of refugees and asylum seekers is estimated to be about 11.5 million [1] plus a much larger number of former refugees who have obtained a residence permit in a new country. A recent systematic review concluded that, worldwide, tens of thousands of (former) refugees who resettled in Western countries probably have post-traumatic stress disorder (PTSD) [2]. Although asylum seekers have been coming to the Netherlands since the 1980s, very few epidemiological studies have focused on this group of inhabitants or on the refugees who have resettled in this country [3-6]. Many population-based studies on adult refugees and asylum seekers living in Western countries report on the prevalence of mental health problems, which mainly concern symptoms of PTSD, depression and anxiety [7], but only a few have investigated general health status and/or physical complaints [5, 6, 8-12]. Most studies were based on relatively small sample sizes and included people from one country of origin only. Furthermore, the majority of studies focused either on refugees or on asylum seekers. However, in European countries, a differentiation can be made between refugees who have obtained a residence permit, because they have been recognized as being in genuine fear of persecution, and asylum seekers who are still in the process of achieving such status (and of whom the majority will never be recognized as a refugee). It would be interesting to compare the two groups because they differ in many aspects. The residence permit gives refugees the opportunity to resettle in the Netherlands. Furthermore, they have already been living in the country for several years and may have found a job and built up a social network. In contrast, asylum seekers are uncertain about obtaining a residence permit, and therefore, their whole future is uncertain. They have just arrived in the Netherlands, have a recent history of traumatic experiences, are living in reception centres and are not allowed to work. A large scale population-based study on adult refugees and asylum seekers from Afghanistan, Iran and Somalia was therefore conducted in the Netherlands to estimate the prevalence rates of physical and mental health problems and to identify the risk factors for these complaints.

\section{METHODS}

An extensive description of the methods, including the selection of the study population and ethnic groups, the chosen outcome measures, the translation and cross-cultural adaptation of the measurement instruments, the training of the interviewers and the practical execution of the study, can be found elsewhere [7].

\section{Study population}

Asylum seekers were approached in 14 randomly selected reception centres in the Netherlands. Random samples of refugees were obtained from the population registers of three municipalities (Arnhem, Leiden and Zaanstad), including adults born in Afghanistan, Iran or Somalia (or if the country of birth was not recorded, at least one parent born in one of these countries). In the groups, a random selection was made of one person per family/address for inclusion in the study. All random samples were obtained by assigning numbers to individuals and then using the random number 
Gerritsen, A.A.M., Bramsen, I., Devillé, W., Willigen, L.H.M. van, Hovens, J.E., Ploeg, H.M. van der

Physical and mental health of Afghan, Iranian and Somali asylum seekers and refugees

living in the Netherlands.

Social Psychiatry and Psychiatric Epidemiology: 41, 2006, nr. 1, p. 18-26

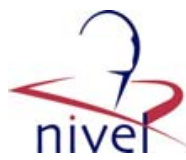

generator of the Statistical Package for the Social Sciences (SPSS) to select the required sample. The plan was to include 100 refugees and 100 asylum seekers per country of origin to make it possible to compare prevalence rates within subgroups. Those who were selected for inclusion in the study were first sent a letter, after which they were contacted by one of 33 specifically trained bilingual interviewers from the three countries of origin. Informed consent was obtained verbally from all respondents, and the study protocol was approved by the Medical Ethics Committee of the VU University Medical Centre in Amsterdam.

\section{Health outcomes}

The current health status of the respondents was measured according to the general health question of the Medical Outcomes Study (MOS) 36-item Short-Form Health Survey (SF-36) [13]. Physical health was measured according to a list of 19 chronic conditions, and the respondents were asked to indicate whether they had had this condition in the previous 12 months. Nine conditions from the screening list used by the Community Health Services for Asylum Seekers were added to the original list. The Harvard Trauma Questionnaire (HTQ) was used to measure symptoms of PTSD [14]. It includes 30 symptoms, the first 16 of which were derived from the Diagnostic and Statistical Manual of Mental Disorders, 4th edition (DSM-IV) criteria for PTSD, and the other 14 describe symptoms related to the traumatic life events of Indochinese refugees. The respondents were asked to indicate the extent to which they were bothered by each symptom in the previous week, ranging from $1=$ not at all to $4=$ extremely. The Hopkins Symptoms Checklist-25 (HSCL-25) was used to measure symptoms of depression (15 items) and anxiety (10 items) [15]. The format of the response options is comparable with that of the HTQ. Because an earlier study on symptoms of depressive illness concluded that the majority of Afghan patients will express death wishes rather than suicidal thoughts, this item was added to the depression scale [16]. Two items describing typical symptoms of distress related to depression in the Iranian culture were also added to the Farsi version of the questionnaire: nârâhati-e qalb (distress of the heart) and nârâhati-e a'sâb (distress of the nerves) [17]. An attempt was made to identify culture- specific symptoms of PTSD, depression and anxiety by giving respondents the opportunity to mention symptoms that were not included in the list. Both the HTQ and the HSCL-25 provide outcomes at symptom level and not at diagnosis level.

\section{Potential risk factors}

The following socio-demographic variables were recorded: residence permit (yes/no), country of origin, gender, age, marital status and whereabouts of spouse, highest level of education completed and period of residence in the Netherlands. Traumatic experiences were assessed with the HTQ, which includes 17 events. To identify traumatic events that are particularly relevant to people from Afghanistan, Iran and Somalia, 15 events were added to the list. The respondents were also asked about any possible stressful experiences that they had encountered in the Netherlands. The checklist included 18 problems, and the respondents were asked to indicate the extent to which any of these problems had bothered them in the previous month $(1=$ not at all to $4=$ extremely). The perceived amount of social support received was measured based on six statements (e.g.

"If I have problems there are people I can turn to"), and the respondents were asked to indicate whether these statements applied to them (yes/no) in the previous month. To estimate the level of acculturation, the respondents were asked if they were feeling at home in the Netherlands. Response items were 'very much/reasonably' and 'a little/not at all'.

Following published guidelines, all questionnaires were crossculturally adapted, translated into Dari, Pashto, Farsi and Somali, back-translated and pretested [18, 19].

\section{Statistical analysis}

Two-tailed Pearson chi-square and Student's $t$ tests were used to examine the differences in sociodemographic variables and other potential risk factors between refugees and asylum seekers.

Differences in health outcomes between the two groups were examined by calculating the odds ratios (ORs), 95\% confidence intervals and $P$ values in univariate logistic regression analyses.

To identify the factors that were independently associated with the health outcomes, multivariate logistic regression analyses were performed by entering all variables simultaneously. Adjusted ORs were calculated to control for the presence of all other variables in the model. 
Gerritsen, A.A.M., Bramsen, I., Devillé, W., Willigen, L.H.M. van, Hovens, J.E., Ploeg, H.M. van der

Physical and mental health of Afghan, Iranian and Somali asylum seekers and refugees

living in the Netherlands.

Social Psychiatry and Psychiatric Epidemiology: 41, 2006, nr. 1, p. 18-26

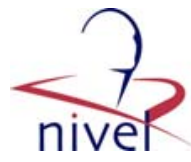

For the univariate and multivariate logistic regression analyses, the response options of all variables were dichotomised:

1. For the SF-36, responses were dichotomised into good (excellent, very good, good) and poor (fair, poor).

2. For the list of chronic conditions, a sum score was calculated based only on the 19 items from the original list, to make the results comparable with data from a health survey among the general and immigrant population of the Netherlands [20]. This sum score (range 0-19) was dichotomised into ' 0 or 1 ' vs 'more than 1 ' chronic condition.

3. For the HTQ (PTSD), individuals with a mean score of $\geq 2.5$ on the 16 PTSD symptoms were considered to be symptomatic.

4. For the HSCL-25, individuals with a mean score of $>1.75$ for depression and/or anxiety and/or the total list of symptoms were considered to be symptomatic.

5. For the HTQ (traumatic experiences), the total number of events experienced was calculated (range 0-17), and for the logistic regression analyses, three groups, which were approximately equal in size, were formed: respondents experiencing 0 to 3, 4 to 7 , and more than 8 traumatic events;

6. For the list with stressful experiences in the Netherlands, a mean score was calculated (range 14 ), which was dichotomised into $<2.5$ and $\geq 2.5$ (low and high levels of post-migration stress, respectively).

7. For the list with social support statements, a sum score was calculated based on the number of positive items (range 0-6), and for the logistic regression analyses, this was dichotomised into $>3$ and $\leq 3$ (high and low levels of social support, respectively).

$P<0.05$ was considered to be statistically significant for all analyses, which were performed with SPSS (version 10.1.4).

\section{RESULTS}

\section{Characteristics of the study population}

For 10 months (June 2003 to April 2004), a total of 479 refugees were approached in various municipalities. Thirty-four refugees did not fulfil the inclusion criteria ( 24 were younger than 18 years old), and 144 could not be reached [60\% were never at home, 34\% were not living (anymore) at the given address]. Of the remaining 301 refugees, 123 were not interviewed mainly because they were too busy or were not interested in participating. This resulted in a response rate of 59\% (178/301) for the total groups of refugees and of 70\% for the Afghan, $53 \%$ for the Iranian and $46 \%$ for the Somali refugees. Of the 178 respondents, $94 \%$ had obtained a residence permit or the Dutch nationality. In the reception centres, 391 asylum seekers were approached, 128 of whom could not be reached $(66 \%$ were no longer living in the centre, $34 \%$ were never at home), and one was younger than 18 years old. Of the remaining 262 asylum seekers, only 30 were unwilling to be interviewed, which resulted in a response rate of $89 \%(232 / 262)$. Of the 232 respondents, $90 \%$ did not (yet) have a residence permit. The number of respondents per country of origin is presented in Table 1 . The respondents and those who could not be reached did not differ in age or gender (both asylum seekers and refugees).

Furthermore, respondents and non-respondents (those reached but not interviewed) did not differ in age (both asylum seekers and refugees) and gender (only asylum seekers); in the municipalities (i.e. refugees), men were more likely to be unwilling to participate.

\section{[ TABLE 1 ]}

Table 1 also compares the characteristics of the refugees and the asylum seekers. There were more men than women in both groups. The refugees were somewhat older (except for the Somali refugees, who were the same age as the asylum seekers) and had resided in the Netherlands for a longer period. There were differences between the subgroups: the Iranian refugees had been in the Netherlands for the longest period (mean 12.0 years, SD 4.2), and the Afghan asylum seekers for the shortest period (mean 2.8 years, SD 1.2). In both groups, the majority was married or living together with a partner (13\% of the entire study population was married, with a spouse living abroad), but the asylum seekers had more often never been married and the refugees had more often been divorced. More than a third 
Gerritsen, A.A.M., Bramsen, I., Devillé, W., Willigen, L.H.M. van, Hovens, J.E., Ploeg, H.M. van der

Physical and mental health of Afghan, Iranian and Somali asylum seekers and refugees

living in the Netherlands.

Social Psychiatry and Psychiatric Epidemiology: 41, 2006, nr. 1, p. 18-26

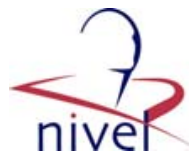

of the asylum seekers had completed only primary school or less, whereas half of the refugees had completed higher education. Asylum seekers had experienced more traumatic events and postmigration stress, and Somali and Afghan asylum seekers had experienced the most traumatic events: 7.6 (SD 3.9) and 7.1 (SD 3.5), respectively, out of 17 events. The most frequently experienced traumatic events included 'forced separation from family members' (66.3\%) and 'unnatural death of family or friend' $(62.3 \%)$. Of the items added to the original list, 'flight to another part of the country' (75.3\%), 'rocket attacks and bombardments' (74.6\%) and 'hiding for a long time' $(62.3 \%)$ were the most common experiences. For the asylum seekers, the items on the post-migratory stressors list with the highest score (1-4) were 'dissatisfaction with the delays in the application for a residence permit' (mean 3.5, SD 0.9) and 'uncertainty about obtaining a residence permit' (mean 3.2, SD 1.1), and for the refugees, 'homesickness' (mean 2.6, SD 1.1) and 'worry about family members left behind' (mean 2.3 , SD 1.2). Among all respondents, nearly $20 \%$ scored 2.5 or more on the list, indicating high levels of post-migration stress. Asylum seekers reported that they experienced less social support compared with the refugees, and nearly half of the asylum seekers did not feel at home in the Netherlands, compared with only a quarter of the refugees. Among the respondents, $30.4 \%$ had a score of 3 or less on the list, classifying them as receiving low levels of social support.

\section{Health outcomes}

In Table 2, the health outcomes of the refugees and the asylum seekers are compared. More asylum seekers than refugees reported a poor general health status, and even $75.9 \%$ of the Iranian asylum seekers considered their health to be poor. In contrast, $64.8 \%$ of the Afghan refugees considered their health to be good. In both groups, approximately half of the respondents suffered from more than one chronic condition. The score was not dichotomised into ' 0 ' vs ' 1 or more' because more than two thirds of all respondents had at least one chronic condition. The mean number of chronic conditions (out of the original list of 19 conditions) was 2.0 (SD 2.3) for the entire study population. The most frequently reported chronic conditions were severe neck/shoulder problems (33.4\%), severe/ chronic back complaints $(32.7 \%)$ and migraine/severe headaches $(32.6 \%)$. Of the items added to the original list, 'dental problems' (44.9\%) and 'eye problems' (33.1\%) were the most common. More asylum seekers than refugees had symptoms of PTSD. The highest rate was found in Iranian asylum seekers (43.4\%), and the lowest rate, in Afghan and Somali refugees (6.0 and 4.0\%, respectively). Since the other 14 symptoms of the HTQ were less specific for the present study population, they were not included in the mean score, although taking these symptoms into account made little change in the results. Depression and anxiety symptoms were more frequently reported among asylum seekers (total scale). Again, the lowest rates were found in Afghan and Somali refugees (28.9 and 16.7\%, respectively). Because the results of the logistic regression analyses were very similar for the depression and anxiety subscales and the total scale, only the latter is presented in this table (and in Table 3). With regard to the subscales, $29.3 \%$ of the refugees and $61.5 \%$ of the asylum seekers reported symptoms on the depression scale, and 27.7 and $41.2 \%$, respectively, on the anxiety scale. On the depression scale, the item 'suicidal thoughts' does not have to be replaced by 'death wishes' because the Afghan respondents scored similarly on both items. However, the item 'distress of the nerves' might be added to the Farsi version of the depression scale because the mean score on this item was high for the Iranian respondents. No other culture-specific symptoms of PTSD, depression or anxiety were identified.

\section{[ TABLE 2 ]}

\section{Factors associated with health outcomes}

Table 3 shows the ORs for the associations between the characteristics of the study population and the health outcomes, adjusted for all other variables listed. As marital status and education were not risk factors for any of the health outcomes, the results of these variables are not presented. In this analysis, the association between legal status (refugee vs asylum seeker) and PTSD symptoms reached just statistical insignificance (when using $P<0.05$ ). The associations between legal status and poor general health and between legal status and depression/anxiety symptoms remained. Respondents from Afghanistan and, in particular, from Iran had a higher risk of having more than one chronic condition (only Iran), PTSD and depression/anxiety symptoms than did respondents from Somalia. Respondents 
Gerritsen, A.A.M., Bramsen, I., Devillé, W., Willigen, L.H.M. van, Hovens, J.E., Ploeg, H.M. van der

Physical and mental health of Afghan, Iranian and Somali asylum seekers and refugees

living in the Netherlands.

Social Psychiatry and Psychiatric Epidemiology: 41, 2006, nr. 1, p. 18-26

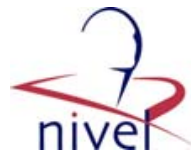

from Iran had a higher risk of poor general health status, PTSD and depression/anxiety symptoms than did respondents from Afghanistan. Female gender was associated with chronic conditions, PTSD and depression/anxiety, whereas higher age was associated with poor general health and chronic conditions. A greater number of experienced traumatic events was associated with all health outcomes, although for general health status and chronic conditions, this was only true for the group who experienced eight or more events. More post-migration stress and less social support were both associated with PTSD and depression/ anxiety symptoms. Not feeling at home in the Netherlands was a risk factor for poor general health only.

\section{[ TABLE 3 ]}

\section{DISCUSSION}

This study showed that more asylum seekers than refugees considered their health to be poor and had symptoms of PTSD and depression/anxiety. Respondents from Afghanistan and, in particular, from Iran had a higher risk of PTSD and depression/anxiety symptoms. Female gender was associated with chronic conditions, PTSD and depression/anxiety, and higher age was associated with poor general health and chronic conditions. A greater number of traumatic events was associated with all health outcomes, and more post-migration stress and less social support were associated with PTSD and depression/anxiety symptoms. Because the study design is cross-sectional, nothing can be said about the direction of causality of some of the associations found; for example, do the stressful experiences in the previous months lead to symptoms of depression/ anxiety in the previous week, or is this the other way around?

The described sampling procedures were intended to produce a representative sample of all refugees and asylum seekers from the three countries under study. Unfortunately, approximately one third of those who were approached could not be reached due either to incorrect address lists or absence from home during the day and the evening on three occasions. However, this is not expected to have caused any systematic bias; by trying to contact respondents three times during the day and the evening, attempts were made to reach also the most (socially) active (and healthy) refugees and asylum seekers. It is not clear to what extent unwillingness to participate may have biased the findings; for example, people with severe health problems could have volunteered to participate, but they may also have been unwilling to participate because they were afraid to be interviewed. Unfortunately, problems with response rate are common in studies on asylum seekers and refugees in the Netherlands [5, 6, 21].

A recently conducted systematic review described the cross-cultural validity and reliability of instruments measuring refugee trauma and health status [22]. The present study included some of the instruments that had either been developed for or adapted and tested in refugee research (HTQ and HSCL-25). However, the validity and reliability of these measurement instruments have not been tested (yet) in the population included in the present study, and no cutoff scores for symptomatic status have been established. Ideally, this study should have included a validation substudy to ascertain the most appropriate cut-off scores for this given population, as suggested by various researchers [22-24]. Nevertheless, the HTQ and the HSCL-25 have been used in several studies on refugees, where the described cut-off scores were also applied. For the HTQ, a scoring algorithm proposed by the Harvard Refugee Trauma Group based on DSM-IV criteria was also used to define respondents with PTSD symptoms, resulting in approximately the same number of cases (77 for the entire study population) as with the cut-off point of 2.5 [25]. Furthermore, all measurement instruments have gone through an extensive translation and cross-cultural adaptation process and have been pre-tested.

In the present study, high ORs for PTSD and depression/ anxiety symptoms were found in the Iranian group compared with the Somali and Afghan groups. The question is: are the prevalence rates among Iranians really much higher, or is there another explanation for these results, e.g. cultural difference in expressing mental health complaints and measurement instruments that are less valid for this population. The latter does not seem likely because differences in prevalence rates were also found for other health outcomes and indicators for the use of health care services (results described elsewhere).

Even after adjusting for other variables, the asylum seekers were found to have higher prevalence rates than did refugees for poor general health, PTSD and depression/anxiety symptoms. It is not expected that many asylum seekers exaggerated their problems because they were informed that 
Gerritsen, A.A.M., Bramsen, I., Devillé, W., Willigen, L.H.M. van, Hovens, J.E., Ploeg, H.M. van der

Physical and mental health of Afghan, Iranian and Somali asylum seekers and refugees

living in the Netherlands.

Social Psychiatry and Psychiatric Epidemiology: 41, 2006, nr. 1, p. 18-26

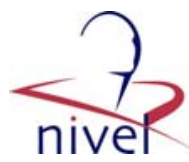

participation in the study would neither help nor hinder their request for asylum. Bearing that in mind, the higher response rate among asylum seekers will probably be mainly due to the fact that they have more time to participate compared with the refugees.

Few studies have addressed the longitudinal course of health problems in refugees and asylum seekers [26-31]. In the present study, one might consider the results of the refugee group as a 5.5-year follow-up measurement of the group of asylum seekers. The period of residence in the Netherlands is highly correlated with legal status (if 5 years is taken as cut-off point, $87 \%$ of the respondents will be correctly classified as asylum seeker or refugee) and is therefore not included in the logistic regression analyses. In these analyses, if legal status is replaced by period of residence in the Netherlands, the ORs for both variables are almost equal. This supports the fact that the study might give an impression of the longitudinal course of health problems (decline in PTSD and depression/ anxiety symptoms and improvement in general health status), including the influence of aspects such as (un) certainty about residing in the Netherlands, living conditions, acculturation, care as usual, etc. However, one could also argue that the group of asylum seekers differs from the group of refugees because they left their country of origin in a different time and under different circumstances (which may explain the difference in the level of education and experienced traumatic events between both groups), and they arrived in the Netherlands in a different political climate (less tolerance towards asylum seekers, and more people are threatened to be sent back to their country of origin). The group of refugees is a sample from the original group of asylum seekers because refugees have been recognized as being in genuine fear of persecution, while the majority of asylum seekers will never be recognized as a refugee (and therefore, the likelihood is that, on average, the refugee sample possibly have more reliable traumatic experiences). As mentioned before, the difference in the number of experienced traumatic events between refugees and asylum seekers might be due to the different situation in the country of origin before they migrated. Another explanation might be that refugees may have forgotten certain events (or suppressed their memories so they can move on with their lives). Current research on the consistency of the memory of asylum seekers and refugees, or of others exposed to traumatic events, find that discrepancies in accounts are likely to occur as time proceeds [32], although reporting about exposure to traumatic events seems to be relatively consistent when the information is obtained in a well-structured manner (like with the HTQ) [33]. Furthermore, it is not totally clear whether these discrepancies lead to an increasing or decreasing number of reported events.

For PTSD, depression and anxiety symptoms, there is a huge range of prevalences reported in population-based studies focusing on adult refugees living in Western countries. The prevalence rates for PTSD symptoms range from 4 to $70 \%$, and similar percentages are reported for the prevalence of symptoms of depression ( 3 to $88 \%$ ) and anxiety ( 2 to $80 \%$ ) [7]. This is due to the fact that the studies are very heterogeneous with regard to the study population (e.g. selection of the study population, country of origin, duration of residence in the country of resettlement and refugee status) and measurement instruments, which makes the comparison of the results of this study with other studies difficult. Only a few studies focusing on the same study population and/or using similar instruments for measuring mental health complaints are found. In a study among 54 Somalian asylum seekers (and refugees) living in reception centres in the Netherlands ( $65 \%$ less than 6 months), prevalence rates of $31.5 \%$ were found for PTSD, $63 \%$ for depression and $36 \%$ for anxiety symptoms, according to the HTQ and the HSCL-25 [6]. In the present study, similar rates for depression (60.0\%) and anxiety (28.6\%), but a somewhat lower rate for PTSD (19.3\%), in Somali asylum seekers were found. A study conducted in the United Kingdom among 180 Somali refugees (and asylum seekers), who had been living there for an average of 8 years, reported a rate of $25 \%$ for depression and/or anxiety symptoms on the HSCL- 25, compared with $16.7 \%$ among the Somali refugees in the present study [34]. In a study among 51 Afghan refugees living for an average of 4 years in the Netherlands, the following prevalence rates were found based on the Composite International Diagnostic Interview: $35 \%$ with a diagnosis of PTSD, 57\% with a diagnosis of depression and $12 \%$ with a diagnosis of anxiety [3]. Similar rates were found in the present study for PTSD (25.4\%) and depression (54.7\%), but a much higher rate was found for anxiety (39.3\%) among Afghan asylum seekers. In a survey conducted in Afghanistan among 1,011 respondents, prevalences of 20.4\% were found for PTSD, 38.5\% for depression and 51.8\% for anxiety, according to the HTQ and HSCL-25 [35]. For the entire group of Afghan respondents in the present study, similar rates were found for PTSD (17.3\%) and depression 
Gerritsen, A.A.M., Bramsen, I., Devillé, W., Willigen, L.H.M. van, Hovens, J.E., Ploeg, H.M. van der

Physical and mental health of Afghan, Iranian and Somali asylum seekers and refugees

living in the Netherlands.

Social Psychiatry and Psychiatric Epidemiology: 41, 2006, nr. 1, p. 18-26

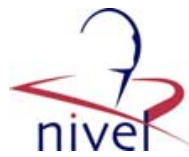

(36.6\%), but a much lower rate for anxiety (32.3\%). A survey conducted in Iran among 35,014 respondents found prevalences of $21 \%$ for depression and $20.8 \%$ for anxiety symptoms using the General Health Questionnaire [36]. We found much higher prevalences among the Iranian asylum seekers $(77.6 \%$ for depression and $58.5 \%$ for anxiety) and refugees $(58.9 \%$ for depression and $41.9 \%$ for anxiety). However, this might be expected, as our study population is composed of a selection of people from the general adult population of Iran with a history of loss and traumatic experiences.

Data on general health status and chronic conditions are only available from a health survey among the Dutch general and immigrant population [20]. In the general population, $18 \%$ considered their health to be poor, compared with $39 \%$ in the immigrant population, which is comparable with the refugee group. In the general population, $30 \%$ suffered from more than one chronic condition, and the mean number of chronic conditions was 1.5 (SD 2.0) for the immigrant population. Both of these figures are lower than the results for the entire study population.

Many factors related to the mental health of refugees and asylum seekers are reported in the literature, and the majority of studies report a positive association with the number of traumatic events experienced and the level of post-migration stress [24, 29, 34, 37-43]. However, there is conflicting evidence with regard to associations with gender, age, marital status and education $[4,24,28,29,34$, $37,40,43,44]$.

\section{CONCLUSION}

Physical as well as mental health problems are highly prevalent among refugees and asylum seekers in the Netherlands. Although among asylum seekers, the prevalence rates are higher for most health outcomes, not only the Community Health Services for Asylum Seekers but also the general health services in the municipalities should be aware of these problems and be able to offer the necessary prevention and treatment facilities. There also seem to be differences between the prevalence rates of people from different countries of origin, and this is a result that could be useful for health care providers and preventive public health activities.

\section{ACKNOWLEDGEMENTS}

The research for this article was funded by the Netherlands Organization for Health Research and Development (project number 2100.0097), who also advised the investigators with regard to the design and execution of the study.

\section{REFERENCES}

1. US Committee for Refugees and Immigrants (2005) World refugee survey 2005. http://www.refugees.org/article. aspx?id= 1342

2. Fazel M, Wheeler J, Danesh J (2005) Prevalence of serious mental disorder in 7000 refugees resettled in Western countries: a systematic review. Lancet 365:1309-1314

3. Gernaat HB, Malwand AD, Laban CJ, Komproe I, de Jong JT (2002) Many psychiatric disorders in Afghan refugees with residential status in Drenthe, especially depressive disorder and post-traumatic stress disorder. Ned Tijdschr Geneeskd 146:1127-1131

4. Hondius AJ, van Willigen LH, Kleijn WC, van der Ploeg HM (2000) Health problems among LatinAmerican and middle eastern refugees in the Netherlands: relations with violence exposure and ongoing sociopsychological strain. J Trauma Stress 13:619-634

5. van den Heuvel WJ (1998) Health status of refugees from former Yugoslavia: descriptive study of the refugees in the Netherlands. Croat Med J 39:356-360

6. Roodenrijs TC, Scherpenzeel RP, de Jong JTVM (1998) Traumatic experiences and psychopathology among Somalian refugees in the Netherlands. Tijdschrift voor Psychiatrie 40:132142

7. Gerritsen AA, Bramsen I, Deville W, van Willigen LH, Hovens JE, van der Ploeg HM (2004) Health and health care utilisation among asylum seekers and refugees in the Netherlands: design of a study. BMC Public Health 4:7

8. Redwood-Campbell L, Fowler N, Kaczorowski J, Molinaro E, Robinson S, Howard M, Jafarpour M (2003) How are new refugees doing in Canada? Comparison of the health and settlement of the Kosovars and Czech Roma. Can J Public Health 94:381-385 
Gerritsen, A.A.M., Bramsen, I., Devillé, W., Willigen, L.H.M. van, Hovens, J.E., Ploeg, H.M. van der

Physical and mental health of Afghan, Iranian and Somali asylum seekers and refugees

living in the Netherlands.

Social Psychiatry and Psychiatric Epidemiology: 41, 2006, nr. 1, p. 18-26

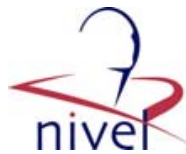

9. Weine SM, Razzano L, Brkic N, Ramic A, Miller K, Smajkic A, Bijedic Z, Boskailo E, Mermelstein R, Pavkovic I (2000) Profiling the trauma related symptoms of Bosnian refugees who have not sought mental health services. J Nerv Ment Dis 188:416-421

10. Cheung P, Spears G (1995) Illness aetiology constructs, health status and use of health services among Cambodians in New Zealand. Aust NZ J Psychiatry 29:257-265

11. vanWilligen LH, Hondius AJ, van der Ploeg HM (1995) Health problems of refugees in the Netherlands. Trop Geogr Med 47:118-124

12. Sinnerbrink I, Silove DM, Manicavasagar VL, Steel Z, Field A (1996) Asylum seekers: general health status and problems with access to health care. Med J Aust 165:634-637

13. McHorney CA,Ware JE Jr, Raczek AE (1993) The MOS 36-Item Short-Form Health Survey (SF36): II. Psychometric and clinical tests of validity in measuring physical and mental health constructs. Med Care 31:247-263

14. Mollica RF, Caspi-Yavin Y, Lavelle J, Tor S, Yang T, Chan S, Pham T, Ryan A, de Marneffe D (1996) Harvard Trauma Questionnaire (HTQ): manual Cambodian, Laotian and Vietnamese versions. Torture 6(Suppl 1):19-33

15. Mollica RF, Wyshak G, de Marneffe D, Tu B, Yang T, Khuon F, Coelho RC, Lavelle J (1996) Hopkins Symptoms Checklist 25 (HSCL-25): manual Cambodian, Laotian and Vietnamese versions. Torture 6(Suppl 1):35-42

16. Waziri R (1973) Symptomatology of depressive illness in Afghanistan. Am J Psychiatry 130:213217

17. Good BJ, DelVecchio Good MJ, Moradi R (1985) The interpretation of Iranian depressive illness and dysphoric affect. In: Kleinman A, Good B (eds) Culture and depression. University of California Press, Berkeley, pp 369-428

18. Beaton DE, Bombardier C, Guillemin F, Ferraz MB (2000) Guidelines for the process of crosscultural adaptation of selfreport measures. Spine 25:3186-3191

19. Bullinger M, Alonso J, Apolone G, Leplege A, Sullivan M, Wood-Dauphinee S, Gandek B, Wagner A, Aaronson N, Bech P, Fukuhara S, Kaasa S, Ware JE Jr (1998) Translating health status questionnaires and evaluating their quality: the IQOLA Project approach. International Quality of Life Assessment. J Clin Epidemiol 51:913-923

20. Westert GP, Schellevis FG, de Bakker DH, Groenewegen PP, Bensing JM, van der Zee J (2005) Monitoring health inequalities through general practice: the Second Dutch National Survey of General Practice. Eur J Public Health 15:59-65

21. Laban CJ, Gernaat HB, Komproe IH, Schreuders BA, de Jong JT (2004) Impact of a long asylum procedure on the prevalence of psychiatric disorders in Iraqi asylum seekers in the Netherlands. J Nerv Ment Dis 192:843-851

22. Hollifield M,Warner TD, Lian N, Krakow B, Jenkins JH, Kesler J, Stevenson J, Westermeyer J (2002) Measuring trauma and health status in refugees: a critical review. JAMA 288:611-621

23. Smith Fawzi MC, Murphy E, Pham T, Lin L, Poole C, Mollica RF (1997) The validity of screening for post-traumatic stress disorder and major depression among Vietnamese former political prisoners. Acta Psychiatr Scand 95:87-93

24. Turner SW, Bowie C, Dunn G, Shapo L, Yule W (2003) Mental health of Kosovan Albanian refugees in the UK. Br J Psychiatry 182:444-448

25. Mollica RF, Sarajlic N, Chernoff M, Lavelle J, Vukovic IS, Massagli MP (2001) Longitudinal study of psychiatric symptoms, disability, mortality, and emigration among Bosnian refugees. JAMA 286:546-554

26. Lie B (2002) A 3-year follow-up study of psychosocial functioning and general symptoms in settled refugees. Acta Psychiatr Scand 106:415-425

27. Beiser M, Hou F (2001) Language acquisition, unemployment and depressive disorder among Southeast Asian refugees: a 10-year study. Soc Sci Med 53:1321-1334

28. Hinton WL, Tiet Q, Tran CG, Chesney M (1997) Predictors of depression among refugees from Vietnam: a longitudinal study of new arrivals. J Nerv Ment Dis 185:39-45

29. Hauff E, Vaglum P (1995) Organised violence and the stress of exile. Predictors of mental health in a community cohort of Vietnamese refugees three years after resettlement. Br J Psychiatry 166:360-367

30. Westermeyer J, Neider J, Callies A (1989) Psychosocial adjustment of Hmong refugees during their first decade in the United States. A longitudinal study. J Nerv Ment Dis 177:132- 139

31. Weine SM, Vojvoda D, Becker DF, McGlashan TH, Hodzic E, Laub D, Hyman L, Sawyer M, Lazrove S (1998) PTSD symptoms in Bosnian refugees 1 year after resettlement in the United States. Am J Psychiatry 155:562-564 
Gerritsen, A.A.M., Bramsen, I., Devillé, W., Willigen, L.H.M. van, Hovens, J.E., Ploeg, H.M. van der Physical and mental health of Afghan, Iranian and Somali asylum seekers and refugees

living in the Netherlands.

Social Psychiatry and Psychiatric Epidemiology: 41, 2006, nr. 1, p. 18-26

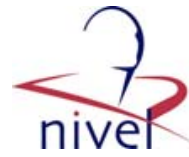

32. Herlihy J, Scragg P, Turner S (2002) Discrepancies in autobiographical memories-implications for the assessment of asylum seekers: repeated interviews study. BMJ 324:324-327

33. Krinsley KE, Gallagher JG, Weathers FW, Kutter CJ, Kaloupek DG (2003) Consistency of retrospective reporting about exposure to traumatic events. J Trauma Stress 16:399-409

34. Bhui K, Abdi A, Abdi M, Pereira S, Dualeh M, Robertson D, Sathyamoorthy G, Ismail H (2003) Traumatic events, migration characteristics and psychiatric symptoms among Somali refugeespreliminary communication. Soc Psychiatry Psychiatr Epidemiol 38:35-43

35. Scholte WF, Olff M, Ventevogel P, de Vries GJ, Jansveld E, Cardozo BL, Crawford CA (2004) Mental health symptoms following war and repression in eastern Afghanistan. JAMA 292:585-593 36. Noorbala AA, Bagheri Yazdi SA, Yasamy MT, Mohammad K (2004) Mental health survey of the adult population in Iran. Br J Psychiatry 184:70-73

37. Steel Z, Silove D, Phan T, Bauman A (2002) Long-term effect of psychological trauma on the mental health of Vietnamese refugees resettled in Australia: a population-based study. Lancet 360:1056-1062

38. Sondergaard HP, Ekblad S, Theorell T (2001) Self-reported life event patterns and their relation to health among recently resettled Iraqi and Kurdish refugees in Sweden. J Nerv Ment Dis 189:838845

39. Blair RG (2000) Risk factors associated with PTSD and major depression among Cambodian refugees in Utah. Health Soc Work 25:23-30

40. Favaro A, Maiorani M, Colombo G, Santonastaso P (1999) Traumatic experiences, posttraumatic stress disorder, and dissociative symptoms in a group of refugees from former Yugoslavia. J Nerv Ment Dis 187:306-308

41. Silove D, Sinnerbrink I, Field A, Manicavasagar V, Steel Z (1997) Anxiety, depression and PTSD in asylum-seekers: associations with pre-migration trauma and post-migration stressors. $\mathrm{Br} \mathrm{J}$ Psychiatry 170:351-357

42. Cheung P (1994) Posttraumatic stress disorder among Cambodian refugees in New Zealand. Int J Soc Psychiatry 40:17-26

43. Fenta H, Hyman I, Noh S (2004) Determinants of depression among Ethiopian immigrants and refugees in Toronto. J Nerv Ment Dis 192:363-372

44. Ai AL, Peterson C, Ubelhor D (2002) War-related trauma and symptoms of posttraumatic stress disorder among adult Kosovar refugees. J Trauma Stress 15:157-160

\section{TABLES}

Table 1 Characteristics of the study population

\begin{tabular}{|c|c|c|c|c|c|}
\hline \multirow[t]{2}{*}{ Characteristic } & \multicolumn{3}{|c|}{ Number $(\%)$ of respondents ${ }^{\mathrm{a}}$} & \multirow[t]{2}{*}{ Statistic } & \multirow[t]{2}{*}{$P$ value } \\
\hline & Total $(N=410)$ & Refugees $(n=178)$ & Asylum seekers $(n=232)$ & & \\
\hline \multicolumn{6}{|l|}{ Country of origin } \\
\hline Somalia & $87(21.2)$ & $25(14.0)$ & $62(26.7)$ & \multirow{4}{*}{ NA } & \multirow[t]{3}{*}{ NA } \\
\hline Afghanistan & $206(50.2)$ & $90(50.6)$ & $116(50.0)$ & & \\
\hline Iran & $117(28.5)$ & $63(35.4)$ & $54(23.3)$ & & \\
\hline \multicolumn{5}{|l|}{ Gender } & \\
\hline Male & $241(58.8)$ & $99(55.6)$ & $142(61.2)$ & \multirow{2}{*}{$x^{2}=1.30$} & \multirow{2}{*}{0.254} \\
\hline Female & 169 (41.2) & 79 (44.4) & $90(38.8)$ & & \\
\hline Mean age (SD) [years] & $37.0(12.4)$ & $40.3(13.3)$ & $34.4(11.1)$ & $t=4.83$ & 0.000 \\
\hline \multicolumn{6}{|l|}{ Marital status } \\
\hline Divorced & $40(9.8)$ & $25(14.0)$ & $15(6.5)$ & \multirow{4}{*}{$x^{2}=8.20$} & \multirow{4}{*}{0.042} \\
\hline Never married & $100(24.4)$ & $36(20.2)$ & $64(27.7)$ & & \\
\hline Married or living together & $252(61.6)$ & $110(61.8)$ & $142(61.5)$ & & \\
\hline Widowed & $17(4.2)(N=409)$ & $7(3.9)$ & $10(4.3)(n=231)$ & & \\
\hline \multicolumn{6}{|l|}{ 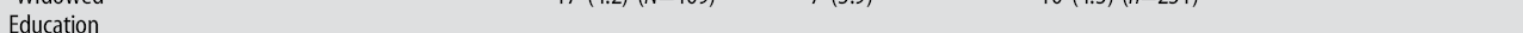 } \\
\hline Vocational/university & $159(38.8)$ & $92(51.7)$ & $67(28.9)$ & \multirow[t]{3}{*}{$x^{2}=29.13$} & \multirow[t]{3}{*}{0.000} \\
\hline Secondary & $142(34.6)$ & $59(33.1)$ & $83(35.8)$ & & \\
\hline None/religious/primary & $109(26.6)$ & $27(15.2)$ & $82(35.3)$ & & \\
\hline Mean time in the Netherlands (SD) [years] & $5.6(4.0)$ & $8.8(4.1)$ & $3.4(1.6)$ & $t=16.98$ & 0.000 \\
\hline Mean number of traumatic events (SD) (0-17) & $6.1(3.7)(N=384)$ & $5.3(3.6)(n=172)$ & $6.8(3.7)(n=212)$ & $t=-4.19$ & 0.000 \\
\hline Mean score for post-migration stressors (SD) (1-4) & $2.0(0.6) \quad(N=381)$ & $1.6(0.4)(n=162)$ & $2.3(0.5)(n=119)$ & $t=-5.60$ & 0.000 \\
\hline Mean sum score for social support (SD) $(0-6)$ & $4.1(1.9)(N=404)$ & $4.8(1.5)(n=177)$ & $3.6(2.0)(n=227)$ & $t=6.78$ & 0.000 \\
\hline \multicolumn{6}{|l|}{ Feeling at home in the Netherlands } \\
\hline Very much/reasonably & $249(60.9)$ & $130(73.0)$ & $119(51.5)$ & \multirow{2}{*}{$x^{2}=19.55$} & \multirow[t]{2}{*}{0.000} \\
\hline A little/not at all & $160(39.1)(N=409)$ & $48(27.0)$ & $112(48.5)(n=231)$ & & \\
\hline
\end{tabular}

NA Not applicable

${ }^{\text {a }}$ Total number of respondents equals total number per group, unless indicated otherwise 
Gerritsen, A.A.M., Bramsen, I., Devillé, W., Willigen, L.H.M. van, Hovens, J.E., Ploeg, H.M. van der Physical and mental health of Afghan, Iranian and Somali asylum seekers and refugees

living in the Netherlands.

Social Psychiatry and Psychiatric Epidemiology: 41, 2006, nr. 1, p. 18-26

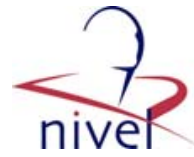

Table 2 Health outcomes

\begin{tabular}{|c|c|c|c|c|c|}
\hline \multirow[t]{2}{*}{ Health outcome } & \multicolumn{3}{|c|}{ Number (\%) of respondents ${ }^{\mathrm{a}}$} & \multirow[t]{2}{*}{ Unadjusted OR (95\% Cl) } & \multirow[t]{2}{*}{$P$ value } \\
\hline & Total $(N=410)$ & Refugees ( $n=178$ ) & Asylum seekers $(n=232)$ & & \\
\hline Poor general health status & $211(51.7)(N=408)$ & $74(42.0)(n=176)$ & $137(59.1)$ & $2.00(1.34-2.96)$ & 0.001 \\
\hline More than one chronic condition & $183(47.5)(N=385)$ & $79(46.5)(n=170)$ & $104(48.4)(n=115)$ & $1.08(0.72-1.62)$ & 0.711 \\
\hline PTSD symptoms & $81(20.6)(N=394)$ & $18(10.6)(n=170)$ & $63(28.1)(n=124)$ & $3.30(1.87-5.84)$ & 0.000 \\
\hline Depression/anxiety symptoms & $210(55.6)(N=378)$ & $65(39.4)(n=165)$ & $145(68.1)(n=213)$ & $3.28(2.15-5.02)$ & 0.000 \\
\hline
\end{tabular}

OR Odds ratio, CI confidence interval, PTSD post-traumatic stress disorder

${ }^{a}$ Total number of respondents equals total number per group, unless indicated otherwise

Table 3 Factors associated with health outcomes

\begin{tabular}{|c|c|c|c|c|c|c|c|c|}
\hline \multirow[t]{2}{*}{ Characteristic } & \multicolumn{2}{|c|}{ Poor general health status } & \multicolumn{2}{|c|}{ More than one chronic condition } & \multicolumn{2}{|l|}{ PTSD symptoms } & \multicolumn{2}{|c|}{ Depression/anxiety symptoms } \\
\hline & Adjusted OR (95\% Cl) & $P$ value & Adjusted OR (95\% Cl) & $P$ value & Adjusted OR (95\% Cl) & $P$ value & Adjusted OR (95\% Cl) & $P$ value \\
\hline \multicolumn{9}{|l|}{ Legal status } \\
\hline Refugees & 1.00 & & 1.00 & & 1.00 & & 1.00 & \\
\hline Asylum seekers & $1.85(1.06-3.25)$ & 0.031 & $1.25(0.70-2.22)$ & 0.453 & $2.49(0.99-6.26)$ & 0.052 & $2.63(1.41-4.93)$ & 0.002 \\
\hline \multicolumn{9}{|l|}{ Country of origin } \\
\hline Somalia & 1.00 & & 1.00 & & 1.00 & & 1.00 & \\
\hline Afghanistan & $0.79(0.40-1.56)$ & 0.497 & $1.81(0.87-3.77)$ & 0.115 & $3.08(1.05-9.07)$ & 0.041 & $2.89(1.22-6.80)$ & 0.015 \\
\hline Iran & $1.66(0.78-3.54)$ & 0.188 & $2.55(1.13-5.74)$ & 0.024 & $18.46(5.19-65.64)$ & 0.000 & $11.11(4.01-30.80)$ & 0.000 \\
\hline \multicolumn{9}{|l|}{ Gender } \\
\hline Male & 1.00 & & 1.00 & & 1.00 & & 1.00 & \\
\hline Female & $1.29(0.76-2.18)$ & 0.340 & $3.02(1.72-5.29)$ & 0.000 & $3.45(1.53-7.78)$ & 0.003 & $2.42(1.30-4.52)$ & 0.005 \\
\hline \multicolumn{9}{|l|}{ Age (years) } \\
\hline $18-27$ & 1.00 & & 1.00 & & 1.00 & & 1.00 & \\
\hline $28-37$ & $1.53(0.77-3.06)$ & 0.223 & $2.14(1.03-4.42)$ & 0.041 & $1.45(0.51-4.14)$ & 0.493 & $1.02(0.45-2.32)$ & 0.966 \\
\hline $38-47$ & $3.79(1.72-8.34)$ & 0.001 & $3.03(1.34-6.85)$ & 0.008 & $2.58(0.76-8.71)$ & 0.127 & $1.04(0.43-2.54)$ & 0.928 \\
\hline$\geq 48$ & $3.50(1.48-8.26)$ & 0.004 & $8.47(3.35-21.40)$ & 0.000 & $1.54(0.44-5.48)$ & 0.501 & $1.71(0.65-4.48)$ & 0.273 \\
\hline \multicolumn{9}{|c|}{ Number of traumatic events $(0-17)$} \\
\hline $0-3$ & 1.00 & & 1.00 & & 1.00 & & 1.00 & \\
\hline $4-7$ & $1.59(0.85-2.96)$ & 0.145 & $1.65(0.86-3.18)$ & 0.133 & $4.82(1.44-16.11)$ & 0.011 & $4.05(1.94-8.45)$ & 0.000 \\
\hline$\geq 8$ & $2.51(1.32-4.75)$ & 0.005 & $3.44(1.72-6.89)$ & 0.000 & $12.18(3.59-41.34)$ & 0.000 & $6.38(2.97-13.74)$ & 0.000 \\
\hline \multicolumn{9}{|c|}{ Mean score for post-migration stressors (1-4) } \\
\hline$<2.5$ & 1.00 & & 1.00 & & 1.00 & & 1.00 & \\
\hline$\geq 2.5$ & $1.90(0.92-3.93)$ & 0.085 & $1.45(0.71-2.93)$ & 0.306 & $4.31(1.93-9.61)$ & 0.000 & $4.48(1.60-12.56)$ & 0.004 \\
\hline \multicolumn{9}{|c|}{ Sum-score for social support $(0-6)$} \\
\hline$>3$ & 1.00 & & 1.00 & & 1.00 & & 1.00 & \\
\hline$\leq 3$ & $0.98(0.54-1.76)$ & 0.945 & $1.04(0.56-1.92)$ & 0.901 & $3.51(1.63-7.53)$ & 0.001 & $2.78(1.36-5.65)$ & 0.005 \\
\hline \multicolumn{9}{|c|}{ Feeling at home in the Netherlands } \\
\hline Very much/reasonably & 1.00 & & 1.00 & & 1.00 & & 1.00 & \\
\hline A little/not at all & $2.31(1.37-3.91)$ & 0.002 & $1.01(0.59-1.73)$ & 0.977 & $2.04(0.98-4.29)$ & 0.058 & $1.71(0.93-3.14)$ & 0.083 \\
\hline
\end{tabular}

Each variable has been adjusted for all other variables listed in the table and for marital status and education (data not shown) OR Odds ratio, Cl confidence interval, PTSD post-traumatic stress disorder 